\title{
The effect of coated sodium butyrate supplementation in sow and nursery diets on lactation performance and nursery pig growth performance
}

Y. D. Jang, M. D. Lindemann ${ }^{*}$, H. J. Monegue, and J. S. Monegue ${ }^{1}$

Department of Animal and Food Sciences, University of Kentucky, Lexington, KY 40546-

0215, United States

*Corresponding author, Tel.: +1 859257 7524; fax: +1 8593231027.

E-mail address: merlin.lindemann@uky.edu (M. D. Lindemann).

${ }^{1}$ Present address: Sioux Nation Ag, 1812 N Cliff Ave, Sioux Falls, SD 57103. 


\section{A B S T R A C T}

Three experiments were conducted to evaluate the effect of coated sodium butyrate (CSB) supplementation to peripartal and lactating sows and nursery pigs on lactation performance and nursery growth performance. In Exp. 1, a total of 43 gestating sows (d 81-92 of gestation) were allotted to $0(n=15), 500(n=16)$, or $1,000(n=12)$ ppm of CSB supplementation based on breed, parity and body weight (BW), and then fed treatment diets until weaning. In Exp. 2 and 3, a total of 144 weanling pigs (72 pigs for Exp. 2 and 3, respectively) from 0 or 1,000 ppm CSB sow treatments in Exp. 1 were allotted within the sow treatment to 0, 500, or 1,000 ppm of CSB supplementation in nursery diets based on breed and BW in a split plot design for a 35-d growth study. All pigs in Exp. 2 were injected with ovalbumin at weaning and d 14 postweaning as an immune challenge. In Exp. 1, there were no differences in sow BW, litter size, litter weight, lactation feed intake or milk composition among treatments. However, colostral $\operatorname{IgG}(P=0.06)$ and $\operatorname{IgA}(P=0.09)$ concentrations tended to increase quadratically as CSB supplementation levels increased. In Exp. 2, pigs from the 1,000 ppm CSB sow treatment had greater BW at d $35(P<0.01)$, average daily gain (ADG; $P<0.01)$, average daily feed intake (ADFI; $P<0.01)$ and feed to gain $(\mathrm{F}: \mathrm{G})$ ratio $(P=0.07)$ than those from the 0 ppm CSB sow treatment. For the nursery treatments, ADG $(P<0.05)$ and ADFI $(P=0.06)$ during the 35-d period increased linearly as CSB supplementation levels increased whereas F:G ratio had a negative quadratic response $(P=0.10)$. In Exp. 3, F:G ratio for d 0-14 
postweaning tended to be lower $(P=0.09)$ in pigs from the $1,000 \mathrm{ppm}$ CSB sow treatment compared with those from the 0 ppm CSB sow treatment whereas BW, ADG, and ADFI $(P<$ 0.05) during the 35-d period decreased linearly as CSB supplementation levels increased in the diets. In conclusion, CSB supplementation tended to increase colostral IgG and IgA concentrations in sows and improved growth performance of nursery pigs under an immune challenge when supplemented in the nursery diet.

Keywords: Coated sodium butyrate; Sow; Reproductive performance; Nursery pig; Growth; 


\section{Introduction}

Butyrate is a short chain fatty acid produced by microbial fermentation in the large intestine of the animal (Bergman, 1990). In swine diets it has been used for nursery pigs to reduce diarrhea and overcome weaning stress (Fang et al., 2014; Piva et al., 2002). Previous studies demonstrated that sodium butyrate (SB) supplementation in the nursery diet improved growth rate, feed efficiency (Le Gall et al., 2009), and porcine intestinal development by increasing villi height, villi height to crypt depth, and mucosa thickness (Lu et al., 2008; Mazzoni et al., 2008). Additionally, it has been reported that SB supplementation enhanced immune function of piglets (Fang et al., 2014) and reduced pro-inflammatory cytokine production such as TNF- $\alpha$ and IL-6 (Wen et al. 2012), and butyric acid had a potential to protect the body from bacterial infection such as E.coli, Enterococcus, and Salmonella (Boyen et al., 2008; Sun et al., 1998). However, most studies supplementing SB in swine diet have focused on nursery pigs where SB was used as an alternative to an antibiotic growth promoter. Thus, the effect of SB supplementation in sow diets has not been as well documented. Because butyrate is an energy source for pigs (Bergman, 1990) and has functions on the immune system and gut integrity including antibacterial and antiinflammatory properties, SB supplementation in sow diets may influence reproductive performance, and pre- and postweaning growth performance of their progeny. Kotunia et al. (2004) reported that piglets fed by artificial milk formulas containing $0.3 \%$ SB on a dry 
matter basis had increased crypt depth, villi height, and mucosa thickness in jejunum and ileum which was associated with increased growth rate. In a recent study, Lu et al. (2012) reported that piglets from the sows that were supplemented with $0.3 \%$ butyrate from late gestation to lactation had increased growth rate at 12 weeks of age. In contrast, Wang et al. (2014) reported no effect of SB supplementation in the lactation diet on litter size, litter growth and lactation feed intake. However, in those studies, response measures were limited to only reproductive performance of sows and growth performance of nursery pigs whereas they lacked information about immunological parameters, milk composition and blood clinical chemistry. Furthermore, it has not been confirmed whether or not there is a carryover effect or interaction when SB is supplemented in both sow and nursery diets. Therefore, the objective of this study was to evaluate effects of SB supplementation in sow and nursery diets on lactation performance, milk composition, colostrum immunoglobulin (Ig) concentrations and nursery growth performance without or with an immune challenge.

\section{Materials and methods}

The experiment was conducted under protocols approved by the University of Kentucky Institutional Animal Care and Use Committee and followed guidelines stated in the Guide for the Care and Use of Agricultural Animals in Agricultural Research and Teaching (FASS, 2010). 


\subsection{Animals, dietary treatments, and housing conditions}

\subsubsection{Experiment 1}

A total of 43 gestating sows (mean parity $=3.6$; Yorkshire, Yorkshire $\times$ Landrace;

Group 1, n=26; Group 2, n=17) artificially inseminated with Duroc semen were allotted to 3 treatments at d 81-92 of gestation in a completely randomized design (CRD) balanced for breed, parity, and body weight (BW). Dietary treatments were: 1) basal diet with 0 ppm of coated sodium butyrate (CSB) supplementation (control), 2) basal diet $+500 \mathrm{ppm}$ of CSB supplementation, and 3) basal diet $+1,000 \mathrm{ppm}$ of CSB supplementation. A commercial product $\left(\mathrm{CM} 3000^{\circledR}\right.$, 30\% microencapsulated SB; Hangzhou King Techina Feed Co., Ltd., China) was used for the experiment. During gestation, pregnant sows were housed individually in gestation stalls $\left(0.57 \times 2.13 \mathrm{~m}^{2}\right)$ and all sows were moved to farrowing crates $\left(1.52 \times 2.13 \mathrm{~m}^{2}\right)$ in an environmentally-controlled farrowing room at $\mathrm{d} 110$ of gestation. The crates had a plastic coated woven wire floor area with heat lamps for piglets and were equipped with a drinking nipple and feed trough for sows. Sows were fed $1.9 \mathrm{~kg} / \mathrm{d}$ of a common gestation diet before being assigned to dietary treatments. Once allotted to treatments, the sows were fed $1.9 \mathrm{~kg} / \mathrm{d}$ of the experimental diets for gestation until farrowing. Farrowing sows were provided $3.2 \mathrm{~kg}$ of the experimental diets for the first 3 days until all feed was consumed in a day. The daily feed allowance was then increased by $0.9 \mathrm{~kg}$ every $3^{\text {rd }}$ 
day until daily feed intake reached at least $6.4 \mathrm{~kg}$, and then sows were provided on an ad libitum basis during lactation.

\subsubsection{Experiments 2 and 3}

In Exp. 2, 72 weanling pigs (Yorkshire $\times$ Landrace $\times$ Duroc, Yorkshire $\times$ Duroc) were selected at weaning from 0 ( $\mathrm{n}=5$ sows) and 1,000 ( $\mathrm{n}=4$ sows) ppm CSB treatments in Exp. 1 to evaluate growth performance under an immune challenge and allotted within the sow treatment to 3 nursery treatments for 3 replicates with 4 pigs per pen ( 2 barrows and 2 gilts) based on breed and BW as a split plot design for a 35-d growth study. In Exp. 3, 72 weanling pigs (Yorkshire $\times$ Landrace $\times$ Duroc, Yorkshire $\times$ Duroc) were selected at weaning from 0 ( $\mathrm{n}=5$ sows) and 1,000 ( $\mathrm{n}=5$ sows) ppm CSB treatments in Exp. 1 to evaluate growth performance with no immune challenge and allotted within sow treatment to 3 nursery treatments for 3 replicates with 4 pigs per pen ( 2 barrows and 2 gilts) based on breed and BW as a split plot design for a 35-d growth study. In both Exp. 2 and 3, the same treatment structure was used. As a split plot design, the main plot was the sow treatment from Exp. 1 (0 and 1,000 ppm of CSB supplementation levels) and the subplot was the CSB supplementation levels in the nursery diet as follows: 1) basal diet with 0 ppm of CSB supplementation (control), 2) basal diet +500 ppm of CSB supplementation, and 3) basal diet $+1,000$ ppm of CSB supplementation. All pigs were housed in raised-deck nursery pens $\left(1.22 \times 1.22 \mathrm{~m}^{2}\right)$ 
with water nipples, plastic feeders, and plastic coated expanded metal flooring. Feed and water were provided on an ad libitum basis. All pigs in Exp. 2 were injected intramuscularly at weaning with $4 \mathrm{mg}$ of ovalbumin (Grade VII, Sigma Chemical, St. Louis, MO) suspended in $1 \mathrm{~mL}$ of a 1:1(volume/volume) solution of PBS and Freunds' incomplete adjuvant (Sigma Chemical) into the trapezius muscle. As an immune challenge, pigs were reinjected at d 14 postweaning. There was no immune challenge pigs in Exp. 3.

\subsection{Experimental diets and diet mixing procedures}

\subsubsection{Experiment 1}

A corn-SBM-based diet was formulated to meet or exceed NRC (1998) nutrient requirement estimates during gestation and lactation (Table 1). The basal diets in gestation and lactation contained 13.85 and $13.79 \mathrm{MJ} / \mathrm{kg}$ of metabolizable energy (ME), $121.1 \mathrm{~g} / \mathrm{kg}$ and $181.9 \mathrm{~g} / \mathrm{kg}$ of crude protein, and 5.4 and $9.7 \mathrm{~g} / \mathrm{kg}$ of total lysine, respectively. For diet mixing, large quantities of the basal diets were mixed and subdivided to which the additive (CSB) was applied; this prevented differences in nontreatment components of the diets. Specifically, a single batch of the basal diet was prepared and then divided into 2 fractions. One of the half fractions was blended with CSB for the diet containing the greatest level of CSB (1,000 ppm) and another one remained unblended (control diet). To make the intermediate diet (500 ppm), a part of the concentrated portion was blended with an equal amount of the unblended basal 
diet.

\subsubsection{Experiments 2 and 3}

A corn-SBM-based diet was formulated to meet or exceed NRC (1998) nutrient requirement estimates during the entire nursery growth trial (Table 2). Diets were formulated in 2 dietary phases (d 0-14 and d 15-35 postweaning for Phases 1 and 2, respectively). The basal diets in Phase 1 and 2 contained 14.28 and $14.25 \mathrm{MJ} / \mathrm{kg}$ of ME, $222.0 \mathrm{~g} / \mathrm{kg}$ and 200.2 $\mathrm{g} / \mathrm{kg}$ of crude protein, and 12.01 and $10.13 \mathrm{~g} / \mathrm{kg}$ of standardized ileal digestible lysine, respectively. In Exp. 2 and 3, the same procedure as used in Exp. 1 was applied to the experimental diet mixing for nursery pigs.

\subsection{Data and sample collection}

\subsubsection{Experiment 1}

Sow BW were measured initially (d 81-92 of gestation), and at d 110 of gestation, farrowing and weaning. Within $24 \mathrm{~h}$ postpartum, the number of total born, born alive, stillborn, and dead pigs were recorded. Piglets were cross-fostered for balancing the number of suckling piglets within 3 days after birth within sow treatment. Individual pig and litter weight were measured at birth and weaning, and lactation feed intake of sows was recorded.

Because of different weaning ages across litters, the piglet BW at weaning was 
normalized by the following equation: Adjusted weaning weight $=\mathrm{BW}$ after cross-fostering + [(BW at weaning $-\mathrm{BW}$ after cross-fostering $) /$ weaning age $] \times 18$

At d 110 of gestation and weaning, blood samples were collected from all sows via jugular venipuncture into SST tubes. Collected blood samples were centrifuged at 1,700 $\mathrm{g}$ for 20 min at $4^{\circ} \mathrm{C}$; serum was aliquoted into microtubes and stored at $-20^{\circ} \mathrm{C}$ until analysis. Colostrum and milk of sows were collected at farrowing and d 11-13 of lactation, respectively, after 20 IU of oxytocin injection (Bimeda, Inc., Oakbrook Terrace, IL, USA), and stored at $20^{\circ} \mathrm{C}$ until analysis. Milk composition analysis was conducted using Foss Milkoscan ${ }^{\mathrm{TM}} \mathrm{FT}$ 120 device (FOSS Electric, Eden Prairie, MN, USA). Serum samples of sows at d 110 of gestation and colostrum samples were submitted to Venture Laboratory (Lexington KY, USA) for total $\operatorname{IgG}$ and $\operatorname{IgA}$ analysis. Measurements for Ig concentrations were determined using ELISA kits following the manufacturer's instructions (Bethyl Laboratories, Montgomery, TX). Assays were done in duplicate. Serum samples of sows at weaning were submitted to North Dakota State University Veterinary Diagnostic Laboratory for blood clinical chemistry analysis.

\subsubsection{Experiments 2 and 3}

Body weight of pigs and feed disappearance were recorded initially (weaning), and at d 14 and d 35 postweaning to calculate average daily gain (ADG), average daily feed intake 
$(\mathrm{ADFI})$, and feed to gain $(\mathrm{F}: \mathrm{G})$ ratio. In Exp. 2, blood samples of pigs were collected via jugular venipuncture into SST tubes initially (weaning before ovalbumin injection), at d 14 and d 35 postweaning. Blood samples were centrifuged at 1,700 g for $20 \mathrm{~min}$ at $4^{\circ} \mathrm{C}$; serum were aliquoted into microtubes and stored at $-20^{\circ} \mathrm{C}$ until analysis. Before analysis, serum samples were pooled within pen. Serum samples were submitted to Venture Laboratory (Lexington KY, USA) for ovalbumin specific IgG, IgA, and IgM analysis. Measurements for ovalbumin specific Ig concentrations were determined using ELISA kits following the manufacturer's instructions (Bethyl Laboratories, Montgomery, TX). Assays were done in duplicate.

\subsection{Statistical analysis}

In Exp. 1, all data were subjected to ANOVA using the GLM procedure in SAS (Statistical Analysis System, Cary, NC) for a CRD. The individual sow and litter served as the experimental unit. The model included the effects of treatment, farrowing group, and interaction between treatment and group. Orthogonal polynomial contrasts were performed to evaluate linear and quadratic effects of CSB supplementation levels. Statistical outliers for Ig concentrations in sow serum ( $\mathrm{n}=2$ of 86 values) and colostrum ( $\mathrm{n}=2$ of 86 values), and for blood clinical chemistry ( $n=9$ of 688 values) of sows were identified using the Grubb's test outlier calculator (GraphPad Software, San Diego, CA, USA) and removed from the data 
analysis. Least squares mean separations were accomplished using the PDIFF option of SAS.

Statistical differences were considered significant at $P<0.05$ and tendency at $P<0.10$.

In Exp. 2 and 3, all data were subjected to ANOVA using the GLM procedure in SAS (Statistical Analysis System, Cary, NC) for a split plot design. The pen served as the experimental unit. The main plot was the sow treatment and the subplot was the nursery treatment. The model included the effects of replicate, sow treatment, nursery treatment, and interactions between sow and nursery treatments and between replicate and sow treatment. Orthogonal polynomial contrasts were performed to evaluate linear and quadratic effects of CSB supplementation levels in the nursery diets. Two pigs (one in 0 ppm CSB sow/500 ppm CSB nursery treatment, and one in 1,000 ppm CSB sow and nursery treatment) in Exp. 2 were removed from the data analysis because of sudden death at $\mathrm{d} 14$ postweaning immediately after secondary ovalbumin injection, and one pig ( 0 ppm CSB sow/500 ppm CSB nursery treatment) in Exp. 3 was removed from the data analysis because of a swollen leg. Feed intake data for the remaining pigs in the pen were adjusted as described by Lindemann and Kim (2007). Statistical outliers for ovalbumin specific Ig concentrations in Exp. 2 were identified within each sampling day using the Grubb's test outlier calculator (GraphPad Software) and removed from the data analysis ( $n=3$ of 54 values for ovalbumin specific IgG; $n=4$ of 54 values for ovalbumin specific IgA). In Exp. 3, because of unequal weaning weight between the sow treatments $(\mathrm{P}<0.05)$, initial $\mathrm{BW}$ in the nursery trial was 
used as a covariate. When there was an interaction between the sow and nursery treatment, further orthogonal polynomial contrasts were performed to evaluate linear and quadratic effects of CSB supplementation levels in the nursery diets within sow treatment. Least squares mean separations were accomplished using the PDIFF option of SAS. Statistical differences were considered significant at $P<0.05$ and tendency at $P<0.10$.

\section{Results}

\subsection{Experiment 1}

There were no differences in sow BW, lactation feed intake, litter size, litter performance (Table 3) or milk composition (Table 4). Even though there was no effect of CSB supplementation in gestation and lactation diets on sow serum IgA and IgG concentrations at d 110 of gestation (Table 5), colostral $\operatorname{IgA}(P=0.09)$ and $\operatorname{IgG}(P=0.06)$ concentrations tended to increase quadratically with increasing CSB supplementation levels in gestation and lactation diets. No effect of CSB supplementation in gestation and lactation diets on blood clinical chemistry of sows was observed except that serum aspartate aminotransferase concentrations tended to increase quadratically as CSB supplementation levels in gestation and lactation diets increased $(P=0.08$; Table 6$)$.

\subsection{Experiment 2}


With regard to the sow treatments, pigs from the 1,000 ppm CSB sow treatment had greater BW at d 14 and 35 postweaning $(P<0.01)$, ADG and ADFI for all phases $(P<0.05)$, and F:G ratio for d $15-35$ postweaning $(P<0.05)$ and overall period $(P=0.07)$ compared with those from the 0 ppm CSB sow treatment (Table 7). For the nursery dietary treatments, linear increases were observed in BW at d 35 postweaning $(P<0.05)$, ADG at $\mathrm{d} 15-35$ postweaning and for the overall period $(P<0.05)$, and ADFI at d $15-35$ postweaning $(P<$ 0.05) and overall period $(P=0.06)$ as CSB supplementation levels in the nursery diets increased whereas BW at d 14 postweaning $(P=0.06)$, ADG at d $0-14$ postweaning $(P=0.07)$, and $\mathrm{F}: \mathrm{G}$ ratio in overall period $(P=0.10)$ had quadratic responses. There were interactions between sow and nursery treatment effects in ADG at d 15-35 postweaning $(P=0.08)$ and F:G at $\mathrm{d} 15-35$ and overall period $(P<0.05)$. Within the 0 ppm CSB sow treatment, a linear increase in ADG at $\mathrm{d} 15-35(P<0.05)$ and quadratic decreases in $\mathrm{F}$ : $\mathrm{G}$ ratio at $\mathrm{d} 15-35$ postweaning $(P=0.06)$ and for the overall period $(P<0.05)$ were observed as CSB supplementation levels in the nursery diets increased whereas that of pigs from the $1,000 \mathrm{ppm}$ CSB sow treatment had no effect of CSB supplementation in the nursery diets.

In the results of ovalbumin specific Ig concentrations in serum of pigs (Table 8), there was no effect of CSB supplementation of either sow or nursery diets in ovalbumin specific $\operatorname{IgM}$ concentrations. However, at weaning, pigs from the 1,000 ppm CSB sow treatment tended to have greater ovalbumin specific IgA concentrations than those from the 0 ppm CSB 
sow treatment $(P=0.09)$. At d 14 postweaning, ovalbumin specific $\operatorname{IgG}$ concentrations in serum of pigs decreased linearly as CSB supplementation levels in the nursery diets increased $(P<0.01)$ whereas ovalbumin specific IgA concentrations in serum of pigs had a quadratic response $(P<0.05)$. There was an interaction between sow and nursery treatment effects on ovalbumin specific IgG concentrations at d $14(P<0.05)$ in which the values decreased quadratically $(P<0.05)$ within the 0 ppm CSB sow treatment by increasing CSB supplementation levels in the nursery diets whereas those values decreased linearly $(P=0.05)$ within the 1,000 ppm CSB sow treatment. At d 35 postweaning, ovalbumin specific IgG concentration showed a large variation.

\subsection{Experiment 3}

Because of unequal weaning weight between the sow treatments, initial BW was used as a covariate in Exp. 3. Pigs from the 1,000 ppm CSB sow treatment tended to have lower F:G ratio for $\mathrm{d} 0-14$ postweaning $(P=0.09)$ compared with those from the 0 ppm CSB sow treatment (Table 9). For the nursery treatments, there were linear decreases in BW at d 35 postweaning $(P<0.05)$, ADG and ADFI at d $15-35$ postweaning and overall period $(P<0.05)$ as CSB supplementation levels in the nursery diets increased whereas there was no difference in $F: G$ ratio. 


\section{Discussion}

The pig industry is currently confronted with several porcine diseases such as PRRS and PED. Sows are highly susceptible to reproductive diseases that lead to reproductive failure, abortion, stillbirth, mummified pigs, as well as a negative impact on sow longevity (Pozzi and Alborali, 2012). For nursery pigs, weaning is one of the largest stresses in the pig's life in which pigs experience physiological, environmental, and social challenges which may result in impaired gut health, immunocompetence, and postweaning growth (Campbell et al., 2013). Therefore, immunity of sows and pigs is important to protect against infectious diseases and challenges and to overcome weaning stress. Sodium butyrate supplementation may facilitate improving gut integrity and development, stimulating immune system, and prevent bacterial colonization in nursery pigs (Rossi et al., 2010; Sun et al., 1998). Therefore, the current study evaluated the effects of CSB supplementation to late gestation and lactation diets of sows and to nursery diets for their progeny on reproductive performance, blood clinical chemistry, colostral Ig concentrations as well as nursery pig performance without or with an immune challenge.

Coated sodium butyrate supplementation in the sow diets had no influence on lactation or litter performance. This result agrees with Wang et al. (2014) who reported that 6,000 ppm of SB supplementation in the lactation diet did not affect litter growth and lactation feed intake when compared to the unsupplemented control diet. In the current study, 
the lack of response in reproductive performance and litter growth might be associated with the short duration of feeding CSB-supplemented diets in gestation and lactation. However, even though there were no differences in milk composition and blood clinical chemistry of sows, CSB supplementation in the diets for late gestation increased colostral $\operatorname{IgA}$ and $\operatorname{IgG}$ concentrations. Limited information is available about the effect of SB on milk composition and colostral immunity of sows. However, Fang et al. (2014) reported that 1,000 ppm of SB supplementation in nursery diets increased serum IgG concentrations of pigs. It has been reported that the entire content of $\operatorname{IgG}$ and $40 \%$ of $\operatorname{IgA}$ in colostrum are derived from sow blood (Bourne and Curtis, 1973). Therefore, even though serum IgG and IgA concentrations of sows at d 110 of gestation were not affected by CSB supplementation, the increase of colostral IgG and IgA may be a result of a stimulation of the immune system by CSB supplementation of sow diets.

In the nursery pig study with an immune challenge herein, both sow and nursery treatment effects, as well as interactions between them were observed. With regard to the sow treatment effect under an immune challenge condition to their pigs, overall growth rate of pigs from the sows in the CSB-supplemented group was improved with increased feed consumption. There is no information about effects of CSB supplementation in sow diets on growth performance of pigs under an immune challenge condition. However, Lu et al. (2012) reported that pigs from sows fed $0.3 \%$ butyrate-supplemented diets from d 77 of gestation to 
lactation had greater BW at d 84 of age than pigs from sows fed a diet with no butyrate supplementation in spite of no additional butyrate supplementation in the nursery diets. One possible explanation for the CSB effect on nursery pigs under immune challenge condition is that the sows consuming CSB-supplemented diets had greater concentrations of colostral IgA and IgG compared with the sows that did not consume CSB. Jang et al. (2013) reported that increased colostral $\mathrm{IgG}$ concentrations from yeast supplementation of sow diets resulted in increased plasma IgG concentrations of their offspring at weaning. Based on that, it is likely that increased colostral IgA and IgG by CSB supplementation in the maternal diets may enhance passive immunity of their progeny resulting in an acquired body defense against immune challenges. Additionally, butyrate may induce fetal hemoglobin synthesis that is associated with increasing the efficiency of $\gamma$-globin gene expression (Weinberg et al., 2005). Therefore, there might be a potential that CSB supplementation in the maternal diet improve growth performance of their progeny under immune challenge condition.

With regard to supplementation of nursery diets under an immune challenge condition, increasing CSB supplementation levels improved overall growth performance of pigs. Several previous studies reported positive effects of SB supplementation in weaning pig diets on postweaning growth, intestinal morphology and microflora (Lu et al., 2008; Piva et al., 2002). Boyen et al. (2008) reported that coated butyric acid supplementation of diets for 6week-old pigs experimentally infected with Salmonella typhimurium decreased fecal 
shedding and intestinal colonization as well as virulence gene expression and epithelial cell invasion by Salmonella typhimurium. Ma et al. (2012) reported that SB supplementation to porcine small intestinal epithelial cells promoted the wound healing process of intestinal mucosa, enhanced mRNA expression of intestinal mucosal tight junction proteins, and increased intestinal antioxidant activities such as superoxide dismutase, glutathione peroxidase, and glutathione. Additionally, Lu et al. (2008) reported that SB supplementation in nursery diets decreased pro-inflammatory cytokine production such as IL-6 and TNF- $\alpha$ that might suppress growth and reduce appetite. Interestingly, interactions between sow and nursery treatments indicated that CSB supplementation in the nursery diet could have more pronounced effect when CSB was not supplemented in the maternal diet.

This is the first study that examined the SB supplementation effect in the maternal and nursery diets on antigen-specific antibody response to ovalbumin. Coated sodium butyrate supplementation in the nursery diet did not elevate the immune response to a foreign antigen which is in contrast with an expected normal immune response to a foreign antigen and the reason for this response is unknown. However, a previous study with mice (Gilbert et al., 2000) has reported that a butyrate derivative treatment to mice by a single i.p. injection produced significantly less ovalbumin-specific antibody under ovalbumin challenge compared to no butyrate treatment and also induced an antigen-specific $\mathrm{T}$ cell inactivation in $\mathrm{CD}^{+} \mathrm{T}$ cells. With the effect of reducing pro-inflammatory cytokine production, butyrate 
might have an immunosuppressive effect (Millard et al., 2002).

When pigs were in a condition without any immune challenge (Exp. 3), different results were observed from pigs under the immune challenge (Exp. 2) in which CSB supplementation in the sow diets might have a positive effect on feed conversion ratio of their offspring only in the early stage of weaning under the normal condition and that in the nursery diets may decrease growth rate with a reduced feed intake. There is limited information about reduced feed intake with CSB supplementation in the nursery diets. Weber and Kerr (2008) reported that feed intake was reduced with increasing SB supplementation levels in the nursery diets. Butyric acid has an unpleasant smell (Lallès et al., 2009) which may limit feed consumption. However, the product used in the current study was a coated salt that reduced smell and allowed slow release of butyrate in the intestine (Leeson et al., 2005; Piva et al., 2007). Thus, the reason for reduced feed intake by CSB supplementation in the nursery diets is still unclear. However, it is clear that feed consumption of pigs under immune challenge increased by increasing CSB supplementation levels in the nursery diets. Therefore, further study is needed to evaluate the effect of different butyrate sources (e.g. butyric acid and butyrate salts) and forms (coated vs. uncoated) on reproductive performance and nursery pig performance.

\section{Conclusion}


The CSB supplementation of late gestation and lactation diets of sows did not affect reproductive performance and litter performance. However, CSB supplementation in the sow diet tended to increase colostral $\operatorname{IgG}$ and $\operatorname{Ig} \mathrm{A}$ concentrations and there was a carryover effect of CSB supplementation in the maternal diets to their progeny in which piglets born and nursed from sows consuming CSB during late gestation and lactation had increased weight gain and feed intake when under an immune challenge condition. Growth rate and feed intake increased as CSB supplementation in the nursery diet increased in the immune challenge condition. However, there was no positive improvement of CSB supplementation in the maternal and nursery diets when pigs were in normal condition without immune challenge. In summation, CSB supplementation tended to enhance colostral immunity and postweaning growth performance of their pigs and improved growth performance of nursery pigs under an immune challenge when supplemented in the nursery diet.

\section{Conflict of interest}

None.

\section{Acknowledgements}

This is publication No. 16-07-063 of the Kentucky Agricultural Experiment Station and is published with the approval of the Director. This work is supported by the National 
Institute of Food and Agriculture, U.S. Department of Agriculture, Multistate project number KY007087 under accession number 1002298. This project was also partially funded by Hangzhou King Techina Feed Co., Ltd., China. Appreciation is expressed to D. Higginbotham for help in diet preparation. 


\section{References}

Bergman, E.N., 1990. Energy contributions on volatile fatty acids from the gastrointestinal tract in various species. Physiol. Rev. 70, 567-590.

Boyen, F., Haesebrouck, F., Vanparys, A., Volf, J., Mahu, M., Van Immerseel, F., Rychlik, I., Dewulf, J., Ducatelle, R., Pasmans, F., 2008. Coated fatty acids alter virulence properties of Salmonella Typhimurium and decrease intestinal colonization of pigs. Vet. Microbiol. 132, 319-327.

Bourne, F.J., Curtis, J., 1973. The transfer of immunoglobulins IgG, IgA, and IgM from serum to colostrum and milk in the sow. Immunology 24, 157-162.

Campbell, J.M., Crenshaw, J.D., Polo, J., 2013. The biological stress of early weaned piglets. J. Anim. Sci. Biotechnol. 4, 19.

Fang, C.L., Sun, H., Wu, J., Niu, H.H., Feng, J., 2014. Effects of sodium butyrate on growth performance, haematological and immunological characteristics of weanling piglets. J. Anim. Physiol. Anim. Nutr. 98, 680-685.

Federation of Animal Science Societies, 2010. Guide for the Care and Use of Agricultural Animals in Research and Teaching, third ed. Federation of Animal Science Societies, Champaign, IL, USA.

Gilbert, K.M., Wahid, R., Fecher, N.P., Freeman, J.P., Fifer, E.K., 2000. Potential clinical use of butyric acid derivatives to induce antigen-specific T cell inactivation. J. Pharmacol. 
Exp. Ther. 294:1146-1153.

Jang, Y.D., Kang, K.W., Piao, L.G., Jeong, T.S., Auclair, E., Jonvel, S., D'Inca, R., Kim, Y.Y., 2013. Effects of live yeast supplementation to gestation and lactation diets on reproductive performance, immunological parameters and milk composition in sows. Livest. Sci. 152, 167-173.

Kotunia, A., Woliński, J., Laubitz, D., Jurkowska, M., Romé, V., Guilloteau, P., Zabielski, R., 2004. Effect of sodium butyrate on the small intestine development in neonatal piglets fed by artificial sow. J. Physiol. Pharmacol. 55 (Suppl. 2), 59-68.

Lallès, J.P., Bosi, P., Janczyk, P., Koopmans, S.J., Torrallardona, D., 2009. Impact of bioactive substances on the gastrointestinal tract and performance of weaned piglets: a review. Animal 3, 1625-1643.

Leeson, S., Namkung,H., Antongiovanni, M., Lee, E. H., 2005. Effect of butyric acid on the performance and carcass yield of broiler chickens. Poult. Sci. 84, 1418-1422.

Le Gall, M., Gallois, M., Sève, B., Louveau, I., Holst, J.J., Oswald, I.P., Lallès, J.P., Guilloteau, P., 2009. Comparative effect of orally administered sodium butyrate before or after weaning on growth and several indices of gastrointestinal biology of piglets. Br. J. Nutr. 102, 1285-1296.

Lindemann, M.D., Kim, B.G., 2007. Technical note: A model to estimate individual feed intake of swine in group feeding. J. Anim. Sci. 85, 972-975. 
Lu, H., Su, S., Ajuwon, K.M., 2012. Butyrate supplementation to gestating sows and piglets induces muscle and adipose tissue oxidative genes and improves growth performance. J. Anim. Sci. 90, 430-432.

Lu, J.J., Zou, X.T., Wang, Y.M., 2008. Effects of sodium butyrate on the growth performance, intestinal microflora and morphology of weanling pigs. J. Anim. Feed Sci. 17, 568-578.

Ma, X., Fan, P.X., Li, L.S., Qiao, S.Y., Zhang, G.L., Li, D.F., 2012. Butyrate promotes the recovering of intestinal wound healing through its positive effect on the tight junctions. J. Anim. Sci. 90, 266-268.

Mazzoni, M., Le Gall, M., De Filippi, S., Minieri, L., Trevisi, P., Wolinski, J., LalattaCosterbosa, G., Lallès, J.P., Guilloteau, P., Bosi, P., 2008. Supplemental sodium butyrate stimulates different gastric cells in weaned pigs. J. Nutr. 138, 1426-1431.

The Merck Veterinary Manual, 2010. Serum Biochemical Reference Ranges. Merck \& Co, Inc., Whitehouse Station, NJ, USA.

Millard, A.L., Mertes, P.M., Ittelet, D., Villard, F., Jeannesson, P., Bernard, J., 2002. Butyrate affects differentiation, maturation and function of human monocyte-derived dendritic cells and macrophages. Clin. Exp. Immunol. 130, 245-255.

NRC, 1998. Nutrient Requirements of Swine, $10^{\text {th }}$ Revised Edition. National Academy Press, Washington, DC, USA. 
Piva, A., Morlacchini, M., Casadei, G., Gatta, P.P., Biagi, G., Prandini, A., 2002. Sodium butyrate improves growth performance of weaned piglets during the first period after weaning. Ital. J. Anim. Sci. 1, 35-42.

Piva, A., Pizzamiglio, V., Morlacchini, M., Tedeschi, M., Piva, G., 2007. Lipid microencapsulation allows slow release of organic acids and natural identical flavors along the swine intestine. J. Anim. Sci. 85, 486-493.

Pozzi, P.S., Alborali, G.L., 2012. Reproductive diseases in sows (Sus scrofa domestica): A review. Isr. J. Vet. Med. 67, 24-33.

Rossi, R., Pastorelli, G., Cannata, S., Corino C., 2010. Recent advances in the use of fatty acids as supplements in pig diets: A review. Anim. Feed Sci. Technol. 162, 1-11.

Sun, C.Q., O'Connor, C.J., Turner, S.J., Lewis, G.D., Stanley, R.A., Roberton, A.M., 1998. The effect of $\mathrm{pH}$ on the inhibition of bacterial growth by physiological concentrations of butyric acid: implications for neonates fed on suckled milk. Chem. Biol. Interact. $113,117-131$.

Wang, J., Yang, M., Xu, S., Lin, Y., Che, L., Fang, Z., Wu, D., 2014. Comparative effects of sodium butyrate and flavors on feed intake of lactating sows and growth performance of piglets. Anim. Sci. J. 85, 683-689.

Weber, T., Kerr, B., 2008. Effect of sodium butyrate on growth performance and response to 
lipopolysaccharide in weanling pigs. J. Anim. Sci. 86, 442-450.

Weinberg, R.S., Ji, X., Sutton, M., Perrine, S., Galperin, Y., Li, Q., Liebhaber, S.A., Stamatoyannopoulos, G., Atweh, G.F., 2005. Butyrate increases the efficiency of translation of gamma-globin mRNA. Blood 105, 1807-1809.

Wen, Z.S., Lu, J.J., Zou, X.T., 2012. Effects of sodium butyrate on the intestinal morphology and DNA-binding activity of intestinal nuclear factor-אb in weanling pigs. J. Anim. Vet. Adv. 11, 814-821. 
Table 1. Formulas and chemical composition of experimental diets in gestation and lactation $(\mathrm{g} / \mathrm{kg}$ asfed basis, Exp. 1). ${ }^{\mathrm{a}}$

\begin{tabular}{|c|c|c|}
\hline Item & Gestation & Lactation \\
\hline \multicolumn{3}{|l|}{ Ingredients } \\
\hline Maize & 833.2 & 675.5 \\
\hline Soybean meal (dehulled, $48 \%$ crude protein) & 100.5 & 256.0 \\
\hline Alfalfa meal & 25.0 & 25.0 \\
\hline Choice white grease & 10.0 & 10.0 \\
\hline Dicalcium phosphate & 15.5 & 12.1 \\
\hline Limestone (ground) & 8.3 & 8.9 \\
\hline Salt (plain) & 5.0 & 5.0 \\
\hline Vitamin premix $^{\mathrm{b}}$ & 1.0 & 1.0 \\
\hline Mineral premix ${ }^{c}$ & 0.5 & 0.5 \\
\hline Choline chloride $(50 \%)^{\mathrm{d}}$ & 1.0 & 1.0 \\
\hline Dynamate $^{e}$ & 0.0 & 5.0 \\
\hline Total & $1,000.00$ & $1,000.00$ \\
\hline \multicolumn{3}{|l|}{ Chemical composition $^{\mathrm{f}}$} \\
\hline Metabolizable energy (MJ/kg) & 13.85 & 13.79 \\
\hline Crude protein & 121.1 & 181.9 \\
\hline Total lysine & 5.4 & 9.7 \\
\hline SID $^{\mathrm{g}}$ lysine & 4.5 & 8.4 \\
\hline Total calcium & 7.5 & 7.3 \\
\hline Total phosphorus & 6.0 & 6.0 \\
\hline
\end{tabular}

${ }^{a}$ Coated sodium butyrate $\left(\mathrm{CM} 3000^{\circledR}\right.$, Hangzhou King Techina Feed Co., Ltd., China) was added to the diet at the assigned levels as mentioned in the material and methods section.

${ }^{\mathrm{b}}$ Supplied per kg of diet: vitamin A, 6,600 IU; vitamin $\mathrm{D}_{3}, 1,320 \mathrm{IU}$; vitamin E, $66 \mathrm{IU}$; vitamin $\mathrm{K}$ (as menadione sodium bisulfite complex), $6.6 \mathrm{mg}$; riboflavin, $8.8 \mathrm{mg}$; pantothenic acid, $22 \mathrm{mg}$; niacin, $88 \mathrm{mg}$; vitamin $\mathrm{B}_{12}, 33 \mu \mathrm{g}$; d-biotin, $0.22 \mathrm{mg}$; folic acid, $1.3 \mathrm{mg}$; and pyridoxine, $6.6 \mathrm{mg}$.

${ }^{\mathrm{c}}$ Supplied per kg of diet: $\mathrm{Zn}, 100 \mathrm{mg}$ as $\mathrm{ZnO} ; \mathrm{Fe}, 120 \mathrm{mg}$ as $\mathrm{FeSO}_{4} \cdot \mathrm{H}_{2} \mathrm{O} ; \mathrm{Mn} 45 \mathrm{mg}$, as $\mathrm{MnO} ; \mathrm{Cu}, 12 \mathrm{mg}$ as $\mathrm{CuSO}_{4} \cdot 5 \mathrm{H}_{2} \mathrm{O} ; \mathrm{I}, 1.5 \mathrm{mg}$ as $\mathrm{CaI}_{2} \mathrm{O}_{6}$; and $\mathrm{Se}, 0.30 \mathrm{mg}$ as $\mathrm{NaSeO}_{3}$.

${ }^{\mathrm{d}}$ Provides $500 \mathrm{mg}$ choline per $\mathrm{kg}$ of diet as choline chloride.

${ }^{\mathrm{e}}$ The product contained $180 \mathrm{~g}$ of K, $110 \mathrm{~g}$ of Mg, and $220 \mathrm{~g}$ of S per kg (Mosaic Feed Ingredients, FL, USA).

${ }^{\mathrm{f}}$ Calculated values.

${ }^{\mathrm{g}}$ Standardized ileal digestible. 
Table 2. Formulas and chemical composition of experimental diets in the nursery period $(\mathrm{g} / \mathrm{kg}$ as-fed basis; Exp. 2 and 3). ${ }^{\mathrm{a}}$

\begin{tabular}{|c|c|c|}
\hline Item & Phase 1 & Phase 2 \\
\hline \multicolumn{3}{|l|}{ Ingredients } \\
\hline Maize & 535.05 & 569.85 \\
\hline Soybean meal (dehulled, $48 \% \mathrm{CP}$ ) & 269.20 & 270.00 \\
\hline Whey (dried) & 100.00 & 100.00 \\
\hline Spray dried animal plasma & 24.00 & 0.00 \\
\hline Fish meal & 30.00 & 20.00 \\
\hline Choice white grease & 20.00 & 20.00 \\
\hline Dicalcium phosphate & 8.00 & 7.00 \\
\hline Limestone (ground) & 7.80 & 7.20 \\
\hline Salt (plain) & 4.00 & 4.00 \\
\hline Vitamin. premix ${ }^{\mathrm{b}}$ & 1.00 & 1.00 \\
\hline Mineral premix $^{c}$ & 0.75 & 0.75 \\
\hline Santoquin $^{\mathrm{d}}$ & 0.20 & 0.20 \\
\hline Total & $1,000.00$ & $1,000.00$ \\
\hline \multicolumn{3}{|l|}{ Chemical composition $^{\mathrm{e}}$} \\
\hline Metabolizable energy (MJ/kg) & 14.28 & 14.25 \\
\hline Crude protein $(\mathrm{CP})$ & 222.0 & 200.2 \\
\hline Total lysine & 13.50 & 11.50 \\
\hline SID $^{f}$ lysine & 12.01 & 10.13 \\
\hline Total calcium & 8.0 & 7.0 \\
\hline Total phosphorus & 6.8 & 6.1 \\
\hline
\end{tabular}

${ }^{a}$ Coated sodium butyrate $\left(\mathrm{CM} 3000^{\circledR}\right.$, Hangzhou King Techina Feed Co., Ltd., China) was added to the diet at the assigned levels as mentioned in the material and methods section.

${ }^{\mathrm{b}}$ Supplied per kg of diet: vitamin A, 6,600 IU; vitamin $\mathrm{D}_{3}, 1,320 \mathrm{IU}$; vitamin E, $66 \mathrm{IU}$; vitamin $\mathrm{K}$ (as menadione sodium bisulfite complex), $6.6 \mathrm{mg}$; riboflavin, $8.8 \mathrm{mg}$; pantothenic acid, $22 \mathrm{mg}$; niacin, $88 \mathrm{mg}$; vitamin $\mathrm{B}_{12}, 33 \mu \mathrm{g}$; d-biotin, $0.22 \mathrm{mg}$; folic acid, $1.3 \mathrm{mg}$; and pyridoxine, $6.6 \mathrm{mg}$.

${ }^{\mathrm{c}}$ Supplied per kg of diet: $\mathrm{Zn}, 100 \mathrm{mg}$ as $\mathrm{ZnO} ; \mathrm{Fe}, 120 \mathrm{mg}$ as $\mathrm{FeSO}_{4} \cdot \mathrm{H}_{2} \mathrm{O} ; \mathrm{Mn} 45 \mathrm{mg}$, as $\mathrm{MnO} ; \mathrm{Cu}, 12 \mathrm{mg}$ as $\mathrm{CuSO}_{4} \cdot 5 \mathrm{H}_{2} \mathrm{O} ; \mathrm{I}, 1.5 \mathrm{mg}$ as $\mathrm{CaI}_{2} \mathrm{O}_{6}$; and $\mathrm{Se}, 0.30 \mathrm{mg}$ as $\mathrm{NaSeO}_{3}$.

${ }^{\mathrm{d}}$ Santoquin (Monsanto, St. Louis, MO, USA) supplied $130 \mathrm{mg}$ ethoxyquin per kg of diet.

${ }^{\mathrm{e}}$ Calculated values.

${ }^{\mathrm{f}}$ Standardized ileal digestible. 
Table 3. Effect of coated sodium butyrate (CSB) supplementation of sow diets on reproductive performance of sows (Exp. 1). ${ }^{\mathrm{a}}$

\begin{tabular}{|c|c|c|c|c|c|c|c|}
\hline \multirow[b]{2}{*}{ Item } & \multicolumn{3}{|c|}{ Treatment, ppm } & \multirow[b]{2}{*}{$\mathrm{SEM}^{\mathrm{c}}$} & \multicolumn{3}{|c|}{$P$-values ${ }^{\mathrm{b}}$} \\
\hline & 0 & 500 & 1000 & & Treatment & Linear & Quadratic \\
\hline No. of sows & 15 & 16 & 12 & & & & \\
\hline \multicolumn{8}{|l|}{ Sow body weight $(\mathrm{kg})$} \\
\hline Initial & 269.0 & 269.6 & 264.5 & 6.5 & 0.85 & 0.64 & 0.71 \\
\hline d 110 of gestation & 277.9 & 277.8 & 273.8 & 6.9 & 0.90 & 0.69 & 0.81 \\
\hline At farrowing & 258.0 & 257.9 & 257.6 & 7.0 & 1.00 & 0.97 & 0.99 \\
\hline At weaning & 259.3 & 260.3 & 257.5 & 6.6 & 0.96 & 0.86 & 0.81 \\
\hline \multicolumn{8}{|l|}{ Litter size (head) } \\
\hline Total born & 13.00 & 12.44 & 13.13 & 0.78 & 0.79 & 0.92 & 0.50 \\
\hline Live born & 12.15 & 11.44 & 11.75 & 0.86 & 0.83 & 0.76 & 0.61 \\
\hline Still born & 0.85 & 1.00 & 1.38 & 0.26 & 0.39 & 0.18 & 0.71 \\
\hline Fostered & 0.20 & 0.13 & 0.00 & 0.58 & 0.97 & 0.82 & 0.97 \\
\hline After cross-foster & 12.35 & 11.56 & 11.75 & 0.50 & 0.49 & 0.42 & 0.41 \\
\hline Weaning & 10.75 & 10.19 & 10.94 & 0.45 & 0.46 & 0.78 & 0.22 \\
\hline Mortality (foster - wean) & 1.60 & 1.38 & 0.81 & 0.43 & 0.46 & 0.23 & 0.74 \\
\hline \multicolumn{8}{|l|}{ Litter weight $(\mathrm{kg})$} \\
\hline Total born & 20.61 & 18.93 & 20.51 & 1.20 & 0.51 & 0.96 & 0.25 \\
\hline Live born & 19.44 & 17.70 & 18.40 & 1.22 & 0.57 & 0.57 & 0.40 \\
\hline After cross-foster & 19.79 & 17.96 & 18.40 & 0.83 & 0.25 & 0.26 & 0.25 \\
\hline Weaning & 69.64 & 64.67 & 68.78 & 3.42 & 0.52 & 0.87 & 0.26 \\
\hline Litter weight gain $(\mathrm{kg} / \mathrm{d})$ & 2.53 & 2.46 & 2.59 & 0.14 & 0.82 & 0.78 & 0.56 \\
\hline \multicolumn{8}{|l|}{ Piglet weight (kg) } \\
\hline Total born & 1.60 & 1.51 & 1.57 & 0.06 & 0.52 & 0.77 & 0.28 \\
\hline Live born & 1.63 & 1.54 & 1.58 & 0.06 & 0.55 & 0.58 & 0.37 \\
\hline After cross-foster & 1.62 & 1.55 & 1.57 & 0.06 & 0.69 & 0.55 & 0.57 \\
\hline Weaning & 6.49 & 6.35 & 6.35 & 0.25 & 0.90 & 0.71 & 0.83 \\
\hline Piglet weight gain (g/d) & 247 & 253 & 245 & 10 & 0.85 & 0.87 & 0.58 \\
\hline Lactation feed intake $(\mathrm{kg} / \mathrm{d})$ & 6.67 & 6.33 & 6.69 & 0.31 & 0.64 & 0.96 & 0.34 \\
\hline Weaning day $(\mathrm{d})$ & 19.70 & 18.94 & 19.50 & 0.41 & 0.35 & 0.74 & 0.17 \\
\hline Adjusted weaning litter weight ${ }^{\mathrm{d}}(\mathrm{kg})$ & 65.32 & 62.30 & 65.02 & 3.00 & 0.71 & 0.95 & 0.42 \\
\hline Adjusted weaning piglet weight ${ }^{\mathrm{d}}(\mathrm{kg})$ & 6.07 & 6.10 & 5.97 & 0.21 & 0.91 & 0.74 & 0.76 \\
\hline
\end{tabular}


Table 4. Effect of coated sodium butyrate (CSB) supplementation of sow diets on milk composition (\%) of sows (Exp. 1). ${ }^{\mathrm{a}}$

\begin{tabular}{lcccccccc}
\hline & \multicolumn{3}{c}{ Treatment, ppm } & & \multicolumn{3}{c}{$P$-values $^{\mathrm{b}}$} \\
\cline { 2 - 3 } Item & 0 & 500 & 1000 & SEM $^{\mathrm{c}}$ & & Treatment & Linear & Quadratic \\
\hline No. of sows & 15 & 16 & 12 & & & & \\
Fat & 6.00 & 6.07 & 5.52 & 0.37 & 0.55 & 0.38 & 0.49 \\
Protein & 4.87 & 4.92 & 4.86 & 0.12 & 0.91 & 0.96 & 0.67 \\
Lactose & 6.00 & 5.89 & 5.99 & 0.06 & 0.36 & 0.95 & 0.16 \\
Total solids & 17.50 & 17.41 & 16.93 & 0.38 & 0.57 & 0.32 & 0.66 \\
Solids non-fat & 11.52 & 11.38 & 11.44 & 0.08 & 0.44 & 0.50 & 0.30 \\
\hline
\end{tabular}

${ }^{a}$ Least squares means. Treatments were: 1) basal diet + 0 ppm CSB supplementation, 2) basal diet +500 ppm of CSB supplementation, and 3) basal diet + 1,000 ppm of CSB supplementation.

${ }^{\mathrm{b}} P$-values include the whole model and the linear and quadratic responses.

${ }^{\mathrm{c}}$ Standard error of means. 
Table 5. Effect of coated sodium butyrate (CSB) supplementation of sow diets on serum and colostrum immunoglobulin concentration $(\mathrm{mg} / \mathrm{dl})$ of sows (Exp. 1). ${ }^{a}$

\begin{tabular}{lcccccccc}
\hline & \multicolumn{3}{c}{ Treatment, ppm } & & \multicolumn{3}{c}{$P$-values $^{\mathrm{b}}$} \\
\cline { 2 - 4 } Item & 0 & 500 & 1000 & SEM $^{\mathrm{c}}$ & & Treatment & Linear & Quadratic \\
\hline No. of sows & 15 & 16 & 12 & & & & \\
Serum at d 110 of gestation & & & & & & & \\
$\quad$ IgA & 100.9 & 115.5 & 115.6 & 16.1 & 0.76 & 0.55 & 0.70 \\
$\quad$ IgG & 1,338 & 1,099 & 1,155 & 115 & 0.13 & 0.30 & 0.28 \\
Colostrum & & & & & & & \\
$\quad$ IgA & 406.1 & 540.4 & 464.3 & 50.5 & 0.15 & 0.44 & 0.09 \\
$\quad$ IgG & 2,447 & 3,337 & 2,724 & 328 & 0.13 & 0.57 & 0.06 \\
\hline
\end{tabular}

${ }^{a}$ Least squares means. Treatments were: 1) basal diet +0 ppm CSB supplementation, 2) basal diet +500 ppm of CSB supplementation, and 3) basal diet $+1,000$ ppm of CSB supplementation.

${ }^{\mathrm{b}} P$-values include the whole model and the linear and quadratic responses.

${ }^{\mathrm{c}}$ Standard error of means. 
Table 6. Effect of coated sodium butyrate (CSB) supplementation of sow diets on blood clinical chemistry of sows at $\mathrm{v}$

\begin{tabular}{lcccccc}
\hline & & \multicolumn{3}{c}{ Treatment, ppm } & & \\
\cline { 3 - 4 } Item $^{\mathrm{c}}$ & Reference range $^{\mathrm{d}}$ & 0 & 500 & 1000 & SEM $^{\mathrm{e}}$ & Treatment \\
\hline No. of sows & & 15 & 16 & 12 & & \\
$\quad$ Total protein (g/dL) & $5.8-8.3$ & 7.21 & 6.96 & 7.18 & 0.15 & 0.45 \\
Albumin (g/dL) & $2.3-4.0$ & 4.21 & 4.35 & 4.40 & 0.11 & 0.45 \\
Globulin (g/dL) & $3.9-6.0$ & 2.79 & 2.64 & 2.76 & 0.13 & 0.67 \\
BUN (mg/dL) & $8.2-25$ & 21.25 & 20.48 & 18.94 & 1.11 & 0.37 \\
ALKP(U/L) & $41-176$ & 48.65 & 40.98 & 44.94 & 4.50 & 0.44 \\
AST (U/L) & $15-55$ & 33.10 & 28.45 & 39.49 & 3.74 & 0.12 \\
GGT (U/L) & $31-52$ & 53.40 & 46.84 & 47.26 & 3.45 & 0.32 \\
CK (U/L) & $66-489$ & 371.1 & 414.9 & 460.9 & 55.9 & 0.55 \\
LDH (U/L) & $160-425$ & 450.6 & 463.1 & 430.8 & 18.7 & 0.50 \\
Creatinine (mg/dL) & $0.8-2.3$ & 1.57 & 1.56 & 1.53 & 0.05 & 0.87 \\
Glucose (mg/dL) & $66-116$ & 73.60 & 76.43 & 71.36 & 2.93 & 0.48 \\
Calcium (mg/dL) & $9.3-11.5$ & 10.59 & 10.55 & 10.52 & 0.20 & 0.97 \\
Phosphorus (mg/dL) & $5.5-9.3$ & 5.71 & 5.80 & 5.62 & 0.21 & 0.83 \\
Sodium (mmol/L) & $139-153$ & 149.0 & 148.6 & 149.3 & 0.8 & 0.81 \\
Potassium (mmol/L) & $4.4-6.5$ & 4.58 & 4.64 & 4.55 & 0.09 & 0.73 \\
Chloride (mmol/L) & $97-106$ & 107.2 & 106.6 & 106.9 & 0.6 & 0.73
\end{tabular}

${ }^{\mathrm{a}}$ Least squares means. Treatments were: 1) basal diet + 0 ppm CSB supplementation, 2) basal diet + 500 ppm of CSB supp 1,000 ppm of CSB supplementation.

${ }^{\mathrm{b}} P$-values include the whole model and the linear and quadratic responses.

${ }^{\mathrm{c}}$ Abbreviation: ALKP, alkaline phosphatase; AST, aspartate aminotransferase; BUN, blood urea nitrogen; CK, creatine transferase; LDH, lactate dehydrogenase;.

${ }^{\mathrm{d}}$ The Merck Veterinary Manual (2010).

${ }^{\mathrm{e}}$ Standard error of means. 
Table 7. Effect of coated sodium butyrate (CSB) supplementation of sow and nursery diets on growth performa ovalbumin challenge (Exp. 2).,

\begin{tabular}{|c|c|c|c|c|c|c|c|c|c|c|c|}
\hline \multirow[b]{3}{*}{ Item } & \multirow{3}{*}{$\begin{array}{l}\text { Sow treatment: } \\
\text { Nursery treatment: }\end{array}$} & \multicolumn{6}{|c|}{ Treatment, ppm } & \multirow[b]{3}{*}{ SEM $^{\mathrm{d}}$} & \multirow{2}{*}{\multicolumn{3}{|c|}{$P-\mathrm{v}$}} \\
\hline & & \multicolumn{3}{|c|}{0} & \multicolumn{3}{|c|}{1,000} & & & & \\
\hline & & 0 & 500 & 1,000 & 0 & 500 & 1,000 & & Sow & Nursery & Sow $\times 1$ \\
\hline \multicolumn{12}{|c|}{ Body weight $(\mathrm{kg})$} \\
\hline d 0 & & 6.94 & 6.88 & 6.90 & 6.93 & 6.86 & 6.89 & 0.03 & 0.76 & 0.18 & 0. \\
\hline d 14 & & 10.22 & 10.07 & 10.34 & 11.14 & 10.56 & 11.09 & 0.20 & $<0.01$ & 0.14 & \\
\hline d 35 & & 20.10 & 21.18 & 22.85 & 23.28 & 22.51 & 23.55 & 0.49 & $<0.01$ & 0.04 & 0. \\
\hline \multicolumn{12}{|l|}{ ADG (kg/d) } \\
\hline $\mathrm{d} 0-14$ & & 0.233 & 0.227 & 0.247 & 0.300 & 0.267 & 0.300 & 0.013 & $<0.01$ & 0.16 & 0. \\
\hline d $15-35^{*}$ & & 0.493 & 0.530 & 0.597 & 0.580 & 0.570 & 0.593 & 0.017 & 0.02 & 0.02 & \\
\hline d 0-35 & & 0.390 & 0.410 & 0.453 & 0.467 & 0.447 & 0.473 & 0.013 & $<0.01$ & 0.04 & 0 \\
\hline \multicolumn{12}{|l|}{ ADFI (kg/d) } \\
\hline d 0-14 & & 0.303 & 0.313 & 0.333 & 0.393 & 0.363 & 0.417 & 0.025 & 0.01 & 0.37 & 0. \\
\hline d $15-35$ & & 0.857 & 0.940 & 0.990 & 1.033 & 0.993 & 1.067 & 0.032 & $<0.01$ & 0.08 & \\
\hline d $0-35$ & & 0.633 & 0.690 & 0.730 & 0.780 & 0.743 & 0.803 & 0.028 & $<0.01$ & 0.13 & 0. \\
\hline \multicolumn{12}{|l|}{ F:G ratio } \\
\hline d 0-14 & & 1.311 & 1.386 & 1.354 & 1.302 & 1.384 & 1.379 & 0.033 & 0.87 & 0.11 & \\
\hline d $15-35^{* *}$ & & 1.722 & 1.776 & 1.666 & 1.789 & 1.747 & 1.795 & 0.022 & 0.02 & 0.38 & \\
\hline d $0-35^{* * *}$ & & 1.623 & 1.689 & 1.598 & 1.662 & 1.662 & 1.689 & 0.020 & 0.07 & 0.23 & 0 \\
\hline
\end{tabular}

${ }^{\mathrm{a}}$ Least squares means of body weight, average daily gain (ADG), average daily feed intake (ADFI), feed to gain (F:G) ratio. description.

${ }^{\mathrm{b}}$ All pigs were injected intramuscularly with $4 \mathrm{mg}$ of ovalbumin at $\mathrm{d} 0$ and 14 postweaning.

${ }^{\mathrm{c}} P$-values include the whole model and the linear and quadratic responses of nursery treatment.

${ }^{\mathrm{d}}$ Standard error of means.

* A linear response $(P<0.05)$ within 0 ppm CSB sow treatment whereas no effect within 1,000 ppm CSB sow treatment $(P>0$

${ }^{* *}$ A quadratic $(P<0.10)$ within $0 \mathrm{ppm}$ CSB sow treatment whereas no effect within $1,000 \mathrm{ppm}$ CSB sow treatment $(P>0.11)$.

${ }^{* * *}$ A quadratic $(P<0.05)$ within 0 ppm CSB sow treatment whereas no effect within 1,000 ppm CSB sow treatment $(P>0.31)$ 
Table 8. Effect of coated sodium butyrate (CSB) supplementation of sow and nursery diets on ovalbumin specific $(\mathrm{mg} / \mathrm{dl})$ of weaning pigs under ovalbumin challenge (Exp. 2). ${ }^{\mathrm{a}, \mathrm{b}}$

\begin{tabular}{|c|c|c|c|c|c|c|c|c|c|c|c|}
\hline \multirow[b]{3}{*}{ Item } & \multirow{3}{*}{$\begin{array}{r}\text { Sow treatment: } \\
\text { Nursery treatment: }\end{array}$} & \multicolumn{6}{|c|}{ Treatment, ppm } & \multirow[b]{3}{*}{ SEM $^{\mathrm{d}}$} & \multirow[b]{3}{*}{ Sow } & \multirow[b]{3}{*}{ Nursery } & \multirow[b]{3}{*}{ Sow } \\
\hline & & \multicolumn{3}{|c|}{0} & \multicolumn{3}{|c|}{1,000} & & & & \\
\hline & & 0 & 500 & 1,000 & 0 & 500 & 1,000 & & & & \\
\hline \multicolumn{12}{|c|}{ Ovalbumin specific IgG } \\
\hline d 0 & & 2.70 & 4.13 & 2.51 & 3.68 & 3.82 & 3.98 & 0.67 & 0.22 & 0.45 & \\
\hline d $14^{*}$ & & 663.6 & 836.6 & 472.9 & 851.7 & 561.8 & 496.4 & 68.3 & 0.72 & 0.01 & \\
\hline d 35 & & 2,456 & 12,942 & 8,660 & 10,683 & 9,407 & 2,543 & 3,262 & 0.86 & 0.29 & \\
\hline \multicolumn{12}{|c|}{ Ovalbumin specific IgA } \\
\hline $\mathrm{d} 0$ & & 0.013 & 0.013 & 0.014 & 0.018 & 0.024 & 0.025 & 0.006 & 0.09 & 0.74 & \\
\hline d 14 & & 0.098 & 0.238 & 0.155 & 0.112 & 0.172 & 0.107 & 0.036 & 0.30 & 0.08 & \\
\hline d 35 & & 0.071 & 0.074 & 0.087 & 0.077 & 0.071 & 0.059 & 0.015 & 0.53 & 0.99 & \\
\hline \multicolumn{12}{|c|}{ Ovalbumin specific IgM } \\
\hline $\mathrm{d} 0$ & & 0.019 & 0.035 & 0.039 & 0.025 & 0.026 & 0.026 & 0.012 & 0.63 & 0.70 & \\
\hline d 14 & & 2.069 & 2.312 & 1.301 & 1.694 & 1.331 & 1.580 & 0.620 & 0.50 & 0.75 & \\
\hline d 35 & & 0.514 & 0.559 & 0.563 & 0.745 & 0.604 & 0.593 & 0.071 & 0.12 & 0.73 & \\
\hline
\end{tabular}

${ }^{\mathrm{a}}$ Least squares means. See the text for the treatment description.

${ }^{\mathrm{b}}$ All pigs were injected intramuscularly with $4 \mathrm{mg}$ of ovalbumin at $\mathrm{d} 0$ and 14 postweaning.

${ }^{\mathrm{c}} P$-values include the whole model and the linear and quadratic responses of nursery treatment.

${ }^{\mathrm{d}}$ Standard error of means.

${ }^{*}$ A quadratic response $(P<0.05)$ within 0 ppm CSB sow treatment and a linear response $(P<0.10)$ within 1,000 ppm CSB so 
Table 9. Effect of coated sodium butyrate (CSB) supplementation of sow and nursery diets on growth performance of challenge (Exp. 3). ${ }^{\mathrm{a}}$

\begin{tabular}{|c|c|c|c|c|c|c|c|c|c|c|}
\hline \multirow{3}{*}{$\begin{array}{r}\text { Sow treatment: } \\
\text { Item } \quad \text { Nursery treatment: }\end{array}$} & \multicolumn{6}{|c|}{ Treatment, ppm } & \multirow[b]{3}{*}{ SEM $^{\mathrm{c}}$} & \multirow[b]{3}{*}{ Sow } & \multirow[b]{3}{*}{ Nursery } & \multirow[b]{3}{*}{ Sow } \\
\hline & \multicolumn{3}{|c|}{0} & \multicolumn{3}{|c|}{1,000} & & & & \\
\hline & 0 & 500 & 1,000 & 0 & 500 & 1,000 & & & & \\
\hline \multicolumn{11}{|l|}{ Body weight $(\mathrm{kg})$} \\
\hline $\mathrm{d} 0^{\mathrm{d}}$ & 7.21 & 7.18 & 7.22 & 7.12 & 7.13 & 7.11 & 0.04 & 0.04 & 0.98 & \\
\hline d 14 & 11.71 & 12.13 & 11.46 & 11.97 & 11.83 & 11.61 & 0.34 & 0.91 & 0.40 & \\
\hline d 35 & 27.16 & 26.80 & 25.04 & 27.42 & 26.14 & 26.27 & 0.62 & 0.69 & 0.07 & \\
\hline \multicolumn{11}{|l|}{$\mathrm{ADG}(\mathrm{kg} / \mathrm{d})$} \\
\hline d 0-14 (Phase 1) & 0.325 & 0.355 & 0.307 & 0.344 & 0.333 & 0.317 & 0.02 & 0.92 & 0.40 & \\
\hline d 15-35 (Phase 2) & 0.735 & 0.699 & 0.647 & 0.736 & 0.681 & 0.698 & 0.02 & 0.52 & 0.01 & \\
\hline d 0-35 (Overall) & 0.571 & 0.561 & 0.511 & 0.579 & 0.542 & 0.546 & 0.02 & 0.69 & 0.07 & \\
\hline \multicolumn{11}{|l|}{ ADFI $(\mathrm{kg} / \mathrm{d})$} \\
\hline d 0-14 (Phase 1) & 0.477 & 0.524 & 0.469 & 0.462 & 0.474 & 0.438 & 0.03 & 0.39 & 0.40 & \\
\hline d 15-35 (Phase 2) & 1.262 & 1.221 & 1.141 & 1.263 & 1.160 & 1.164 & 0.03 & 0.73 & 0.03 & \\
\hline d 0-35 (Overall) & 0.948 & 0.942 & 0.872 & 0.942 & 0.886 & 0.873 & 0.03 & 0.54 & 0.10 & \\
\hline \multicolumn{11}{|l|}{$\mathrm{F}: \mathrm{G}$ ratio } \\
\hline d 0-14 (Phase 1) & 1.449 & 1.489 & 1.524 & 1.345 & 1.422 & 1.391 & 0.05 & 0.09 & 0.37 & \\
\hline d 15-35 (Phase 2) & 1.711 & 1.746 & 1.766 & 1.716 & 1.705 & 1.667 & 0.03 & 0.23 & 0.93 & \\
\hline d 0-35 (Overall) & 1.654 & 1.678 & 1.708 & 1.627 & 1.636 & 1.602 & 0.03 & 0.13 & 0.84 & \\
\hline
\end{tabular}

${ }^{\mathrm{a}}$ Least squares means of body weight, average daily gain (ADG), average daily feed intake (ADFI), feed to gain (F:G) rat description.

${ }^{\mathrm{b}} P$-values include the whole model and the linear and quadratic responses of nursery treatment.

${ }^{\mathrm{c}}$ Standard error of means.

${ }^{\mathrm{d}}$ Initial body weight was used as a covariate because of unequal weaning weights in the sow treatments. 